\title{
Influência da localização das fezes nas características morfogênicas e estruturais e no acúmulo de forragem em pastos de capim-braquiária
}

\section{Manoel Eduardo Rozalino Santos ${ }^{1}$, Dilermando Miranda da Fonseca ${ }^{2}$, Thiago Gomes dos Santos Braz ${ }^{1}$, Guilherme Portes Silva ${ }^{3}$, Virgílio Mesquita Gomes ${ }^{1}$, Simone Pedro da Silva ${ }^{4}$}

1 Doutorando do Departamento de Zootecnia - Universidade Federal de Viçosa.

2 Departamento de Zootecnia - Universidade Federal de Viçosa.

${ }^{3}$ Graduando do Departamento de Agronomia - Universidade Federal de Viçosa.

${ }^{4}$ Mestranda do Departamento de Zootecnia - Universidade Federal de Viçosa.

RESUMO - Objetivou-se avaliar as características morfogênicas e estruturais e o acúmulo de forragem em pastos de Brachiaria decumbens (capim-braquiária) de acordo com a localização das fezes de bovinos. Foram avaliadas duas áreas da pastagem: próxima e distante das fezes. O delineamento foi em blocos casualizados, com três repetições. Foram marcados perfilhos no pasto para avaliação do comprimento de folhas e colmos. O aparecimento e a morte de folhas também foram registrados. A taxa de alongamento de colmo foi $80 \%$ maior e a taxa de alongamento foliar $23 \%$ maior nos perfilhos das áreas próximas das fezes. O filocrono também foi maior nos perfilhos (8,5 dias) das áreas próximas às fezes em comparação àqueles de áreas distantes $(7,7$ dias). Não houve efeito da localização das fezes sobre a taxa de senescência foliar (0,39 cm/perfilho.dia) e a duração de vida da folha (38 dias). O comprimento final da lâmina foliar foi $25 \%$ maior nos perfilhos localizados próximos às fezes. O número de folhas com desfolhação (1,3 folhas) foi menor nas áreas próximas às fezes, contrariamente ao número de folhas mortas (2,8 folhas). O comprimento do pseudocolmo aumentou 73\% com a proximidade das fezes. Os números de perfilhos vegetativos, mortos e total foram maiores nas áreas distantes das fezes. Maior taxa de crescimento total do capim-braquiária também ocorreu nas áreas próximas às fezes. A deposição de fezes bovinas modifica as características morfogênicas e a estrutura do pasto de $B$. decumbens. Nas regiões próximas às fezes, o fluxo de tecidos é mais intenso e o acúmulo de forragem é maior.

Palavras-chave: Brachiaria decumbens, colmo, fluxo de tecidos, folha, perfilho

\section{Influence of localization of feces on morphogenetic and structural characteristics and forage accumulation on Brachiaria decumbens pastures}

\begin{abstract}
The objective of this study is to evaluate morphogenetic and structural characteristics as well as forage accumulation on Brachiaria decumbens pastures according to the site of cattle feces. It was evaluated two grazing areas: near and far from the droppings. The design used was a random block design, with three replicates. Tillers were tagged on the pasture for evaluation of length of the leaves and stems. Leaf appearance and death were also recorded. Stem elongation rate was $80 \%$ higher and leaf elongation rate was $23 \%$ higher for the tillers near the dropping areas. Phyllochron was also higher for tillers (8.5 days) in sites close to the feces in comparison to those from the distant areas (7.7 days). There was no effect of dropping localization on leaf senescence rate $(0.39 \mathrm{~cm} /$ tiller.day) and leaf life span (38 days). Final leaf blade length was $25 \%$ higher for tillers near the droppings. The number of defoliating leaves (1.3 leaf) was lower in areas near the droppings, contrary to the number of dead leaves (2.8 leaves). Pseudostem length increased $73 \%$ as it was closer to the droppings. Number of dead and total vegetative tiller was higher in areas far from the droppings. Higher total growth rate of $B$. decumbens also occurred in sites close to the droppings. Cattle droppings change the morphogenetic characteristics and structure of $B$. decumbens pasture. In areas close to the feces, the tissue flow is more intense and forage accumulation is higher.
\end{abstract}

Key Words: Brachiaria decumbens, leaf, stem, tiller, tissues flow

\section{Introdução}

A produtividade da planta forrageira decorre da contínua emissão de folhas e perfilhos, processos importantes para restauração da área foliar após desfolhação e para a perenidade do pasto. O desenvolvimento de folhas é fundamental para o crescimento vegetal, dado o papel das folhas na fotossíntese, ponto de partida para a síntese de tecidos (Gomide \& Gomide, 2000). 
O desenvolvimento do colmo também influencia a produção de forragem porque, dependendo do estádio de desenvolvimento do perfilho, o colmo tem prioridade na partição de fotoassimilados. Ademais, o colmo pode favorecer a fotossíntese do dossel pela redução do seu coeficiente de extinção de luz (Gomide et al., 2003). Contudo, o alongamento do colmo compromete o valor nutritivo e a estrutura do pasto, fatores determinantes do desempenho animal.

O melhor entendimento da dinâmica de produção de forragem pode ser obtido pelo estudo da morfogênese. Em pastos onde apenas folhas são produzidas, a morfogênese de plantas pode ser descrita por três características principais: taxa de aparecimento foliar, taxa de alongamento foliar e duração de vida da folha. Estas são determinadas geneticamente, mas também são influenciadas pelo clima e pelo manejo. A combinação das características morfogênicas determina as três principais características estruturais do pasto: tamanho da folha, densidade populacional de perfilhos e número de folhas vivas por perfilho (Chapman \& Lemaire, 1993).

A deposição de fezes pelos bovinos é forma de distribuição de nutrientes que ocorre irregularmente na pastagem, o que pode resultar em zonas mais ou menos favoráveis ao crescimento do pasto. Mesmo assim, a reciclagem dos nutrientes via fezes excretadas por estes animais é importante para sustentabilidade da pastagem, especialmente quando não há reposição de nutrientes por meio de fertilizações (Braz et al., 2002).

O maior alongamento de folha e colmo proporcionado pelos nutrientes advindos das fezes modifica o índice de área foliar do pasto e, com efeito, sua capacidade em acumular biomassa. A distribuição das fezes modifica não apenas a estrutura vertical do pasto, mas também sua estrutura horizontal, que é importante em todas as escalas da interação planta-animal (Carvalho et al., 2001).

Com este trabalho, objetivou-se avaliar o efeito da deposição natural de fezes bovinas sobre as características morfogênicas, estruturais e o acúmulo de forragem em pastos de Brachiaria decumbens manejados sob lotação contínua.

\section{Material e Métodos}

Este trabalho foi conduzido de novembro de 2007 a maio de 2008 em área de pastagem de Brachiaria decumbens cv. Basilisk (Stapf.) (capim-braquiária), estabelecida em 1997, com aproximadamente $10.000 \mathrm{~m}^{2}$, pertencente ao Setor de Forragicultura do Departamento de Zootecnia da Universidade Federal de Viçosa (204' S; 420 $51^{\prime}$ W; 651 m). A área experimental era constituída de três piquetes de cerca de 0,30 ha, além de uma área reserva. O solo da área experimental é Latossolo Vermelho-Amarelo de textura argilosa (Embrapa, 1999). A análise química do solo, realizada no início do período experimental, na camada $0-20 \mathrm{~cm}$, apresentou os seguintes resultados: $\mathrm{pH}$ em $\mathrm{H}_{2} \mathrm{O}: 5,4$; $\mathrm{P}: 1,5$ (Mehlich-1) e K: $88 \mathrm{mg} / \mathrm{dm}^{3} ; \mathrm{Ca}^{2+}: 1,88 ; \mathrm{Mg}^{2+}: 0,47 \mathrm{e} \mathrm{Al}^{3+}$ : $0,16 \mathrm{cmol}_{\mathrm{c}} / \mathrm{dm}^{3}(\mathrm{KCl} 1 \mathrm{~mol} / \mathrm{L})$. Durante o período de avaliação os dados climáticos foram registrados em estação meteorológica distante da área experimental aproximadamente $500 \mathrm{~m}$ (Tabela 1).

A adubação fosfatada foi efetuada no dia 16 de janeiro de 2008, com aplicação de $70 \mathrm{~kg} / \mathrm{ha}$ de $\mathrm{P}_{2} \mathrm{O}_{5}$, na forma de superfosfato simples, em toda área experimental. A adubação nitrogenada, na forma de uréia, foi realizada em três aplicações de $50 \mathrm{~kg} / \mathrm{ha}$ de $\mathrm{N}$ ao final da tarde de cada data de aplicação (16/1/2008, 26/2/2008 e 7/4/2008).

A partir de novembro de 2007, os piquetes foram manejados sob lotação contínua com taxa de lotação variável a fim de manter a altura do pasto em torno de $25 \mathrm{~cm}$. Para isso, a altura do pasto foi monitorada duas vezes por semana e foram utilizados bovinos machos, em recria, com peso médio de $200 \mathrm{~kg}$. O monitoramento das alturas dos pastos nos piquetes foi realizado por meio de medidas em 50 pontos de cada piquete, utilizando-se instrumento construído com dois tubos de PVC, um no interior do outro. O tubo interno possui escala com divisões de $1 \mathrm{~cm}$ e uma haste fixa e metálica (prego) que desliza ao longo de uma fenda no tubo externo. O critério para a mensuração da altura do pasto correspondeu à distância desde a superfície do solo até as folhas localizadas na parte superior do dossel.

Tabela 1 - Temperatura média diária, insolação, precipitação pluvial total mensal e evaporação total mensal durante os meses de novembro de 2007 a maio de 2008

\begin{tabular}{lcccc}
\hline Mês & Temperatura média do ar $\left({ }^{\circ} \mathrm{C}\right)$ & Insolação (horas/dia) & Precipitação pluvial $(\mathrm{mm})$ & Evaporação $(\mathrm{mm})$ \\
\hline Novembro de 2007 & 21,9 & 4,9 & 52,6 & 175,7 \\
Dezembro de 2007 & 22,9 & 10,7 & 219,5 & 87,7 \\
Janeiro de 2008 & 21,6 & 8,2 & 112,7 & 92,4 \\
Fevereiro de 2008 & 22,7 & 8,5 & 239,2 & 634,6 \\
Março de 2008 & 22,0 & 6,1 & 62,6 & 67,1 \\
Abril de 2008 & 21,5 & 6,4 & 4,6 & 55,5 \\
Maio de 2008 & 17,8 & 7,4 & 66,2 \\
\hline
\end{tabular}


Foram avaliadas duas áreas na pastagem, uma próxima e outra distante das fezes. Considerou-se próxima das fezes a área imediatamente adjacente às fezes, enquanto a área distante correspondeu aos locais do pasto em que, num raio de cerca de $1 \mathrm{~m}$, não havia presença de fezes. Adotou-se o delineamento em blocos ao acaso com três repetições.

No início de janeiro de 2008, o pasto de capim-braquiária foi infestado pela lagarta Mocis latipes, o que impediu a realização e continuidade das avaliações em campo, que haviam iniciado em meados de dezembro de 2007. Com a infestação da lagarta, retiraram-se os animais dos piquetes e fez-se aplicação do inseticida do grupo piretróide (Decis 25EC) na dose de $200 \mathrm{~mL} / \mathrm{ha}$. Os piquetes foram novamente utilizados, sob pastejo e seguindo o mesmo manejo anterior, somente a partir de meados de fevereiro de 2008. De março a abril de 2008, avaliações foram realizadas no pasto de capim-braquiária.

As características morfogênicas e estruturais dos perfilhos foram avaliadas em áreas do pasto que representavam, inicialmente, sua condição média ( $25 \mathrm{~cm}$ de altura). No início dessas avaliações, escolheram-se áreas próximas de fezes frescas, que, provavelmente, haviam sido depositadas recentemente na área; além de áreas distantes das fezes. Em cada piquete, foram marcados 16 perfilhos por meio de anel plástico colorido, sendo oito próximos às placas de fezes e os demais, distantes. Foram avaliados dois ciclos de coleta de dados, de no mínimo quatro semanas. Em cada ciclo, um novo grupo de perfilhos foi selecionado para avaliação.

Com o auxílio de uma régua graduada, foram efetuadas medições do comprimento das lâminas foliares e do pseudocolmo dos perfilhos marcados, duas vezes por semana. O comprimento das folhas expandidas foi medido desde a ponta da folha até sua lígula. No caso de folhas em expansão, o mesmo procedimento foi adotado, porém considerou-se a lígula da última folha expandida como referencial de mensuração. Para folhas em senescência, o comprimento correspondeu à distância entre o ponto até onde o processo de senescência avançou até a lígula da folha. O tamanho do colmo foi mensurado como a distância desde a superfície do solo até a lígula da folha mais jovem completamente expandida. A partir dessas informações foram calculadas as variáveis: número de folhas com desfolhação por perfilho: número médio de folhas por perfilho com remoção parcial ou total da lâmina foliar; número de folhas vivas por perfilho (NFV): número médio de folhas por perfilho em alongamento e expandidas, incluindo as folhas pastejadas; número de folhas mortas por perfilho: número médio de folhas por perfilho com mais de 50\% da lâmina foliar senescente; número de folhas totais por perfilho: somatório do número médio por perfilho de folhas viva e morta; comprimento final da lâmina foliar: comprimento médio de todas as folhas presentes no perfilho; comprimento do pseudocolmo: comprimento médio dos pseudocolmos; taxa de aparecimento foliar: número de folhas surgidas por perfilho dividido pelo número de dias do período de avaliação; filocrono: inverso da taxa de aparecimento foliar; taxa de alongamento foliar: somatório de todo alongamento da lâmina foliar por perfilho dividido pelo número de dias do período de avaliação; duração de vida da folha (DVF): estimada pela equação DVF $=\mathrm{NFV} \times$ Filocrono (Lemaire \& Chapman, 1996); taxa de senescência foliar: variação média e negativa no comprimento da lâmina foliar, resultado da diminuição da porção verde da lâmina foliar, dividido pelo número de dias do período de avaliação; taxa de alongamento de colmo: somatório de todo alongamento de colmo e, ou, pseudocolmo por perfilho dividido pelo número de dias do período de avaliação; taxa de acúmulo de folha: diferença entre as taxas de crescimento e senescência de folha; taxa de crescimento: somatório das taxas de alongamento de colmo e de folha; acúmulo de forragem: somatório das taxas de alongamento de colmo e de acúmulo de folha.

No último dia de cada período de avaliação, todos os perfilhos foram cortados ao nível do solo, colocados em sacos plásticos identificados e levados ao laboratório. As folhas e colmos foram separados e tiveram seus comprimentos medidos, de forma similar àquela realizada no campo e, depois, foram levados à estufa a $65^{\circ} \mathrm{C}$ por 48 horas. Após a secagem, o material foi pesado e a massa de cada componente morfológico dividida pelo seu comprimento total correspondente. Assim, obteve-se o fator de conversão $(\mathrm{mg} / \mathrm{mm})$ utilizado para transformar todas as leituras realizadas no campo (expressas em $\mathrm{cm} /$ perfilho.dia) em $\mathrm{mg}$ /perfilho.dia. O acúmulo de forragem, em kg/ha.dia de massa seca, foi calculado pela multiplicação desses valores (mg/perfilho.dia) pela densidade populacional média de perfilhos vivos em cada unidade experimental, sendo esse resultado dividido por 100 .

A determinação da densidade populacional de perfilhos ocorreu na última semana de março. Escolheram-se áreas do pasto próximas de fezes que, provavelmente, não haviam sido depositadas recentemente na pastagem, devido seu aspecto mais consistente. Já a escolha das áreas distantes das fezes ocorreu de maneira semelhante à descrita anteriormente. Foram colhidas seis amostras de forragem por piquete, sendo três amostras oriundas de cada área do pasto (próxima e distante das fezes), com corte ao nível do solo de todos os perfilhos contidos no interior de um quadrado de $0,25 \mathrm{~m}$ de lado. Esses perfilhos foram acondicionados em sacos plásticos identificados e, em 
seguida, levados para o laboratório, onde foram quantificados e classificados. Os perfilhos vivos que tinham a inflorescência visível foram classificados como reprodutivos; os vivos que não tinham a inflorescência visível foram denominados de vegetativos; e aqueles cujo colmo estava totalmente necrosado foram classificados como mortos. O somatório dos perfilhos vegetativos e reprodutivos correspondeu aos perfilhos vivos. A soma dos perfilhos vivos e mortos foi denominada perfilhos totais.

As análises dos dados experimentais foram feitas usando o Sistema para Análises Estatísticas - SAEG, versão 8.1 (Universidade Federal de Viçosa, 2003). Para cada característica, foi realizada a análise de variância e a aplicação do teste F. Todas as análises estatísticas foram realizadas ao nível de significância de até 10 \% de probabilidade.

\section{Resultados e Discussão}

Como as características morfogênicas são determinantes da produção da planta forrageira e da estrutura do pasto, torna-se relevante conhecer o efeito da deposição natural das fezes de bovinos sobre a morfogênese do pasto. Nesse sentido, houve influência $(\mathrm{P}<0,10)$ das fezes dos bovinos sobre a taxa de alongamento de colmo, taxa de alongamento foliar, taxa de aparecimento foliar e filocrono. Todavia, as fezes dos bovinos não influenciaram $(\mathrm{P}>0,10)$ a taxa de senescência foliar, a duração de vida da folha e a taxa de acúmulo de folhas (Tabela 2).

A taxa de alongamento de colmo foi $80 \%$ maior na área próxima das fezes $(0,27 \mathrm{~cm} /$ perfilho.dia $)$ que na área distante $(0,15 \mathrm{~cm} /$ perfilho.dia). A taxa de alongamento foliar foi $22,86 \%$ superior nos perfilhos próximos das fezes $(1,72$ cm/perfilho.dia) em comparação aos das áreas distante das fezes (1,40 cm/perfilho.dia) (Tabela 2). Esse maior alongamento de folhas e colmos em áreas próximas das fezes indica maior presença de fatores de crescimento nessas áreas do pasto, notadamente de nutrientes oriundo da mineralização das fezes. Em condições de maior disponibilidade de nutrientes, como o nitrogênio, a taxa de alongamento de folhas da $B$. decumbens aumenta (Fagundes et al., 2006; Silva et al., 2009).

Outro fator que pode explicar as maiores taxas de alongamento de folhas e colmos nos perfilhos próximos das fezes consiste na formação de um microclima diferenciado em volta das fezes, o que poderia favorecer, principalmente, as condições de umidade do solo. Esta maior umidade poderia otimizar a absorção de nutrientes pela forrageira, especialmente daqueles cujo mecanismo de transporte no solo ocorre por fluxo de massa, como o nitrogênio.

É importante destacar que, durante a avaliação dos perfilhos marcados, observou-se presença de besouros nas placas de fezes, o que pode ter acelerado a mineralização da matéria orgânica e disponibilização de nutrientes. Realmente, besouros da família Scarabaeidae e outros organismos coprófagos aceleram a reciclagem de nutrientes, pois, na presença desses, a incorporação das fezes pode ser feita em 24 horas, promovendo rápida mineralização, redução da volatilização da amônia e, consequentemente, contribuindo para maior retenção dos nutrientes no sistema solo-planta-animal (Moot \& Popenoe, 1977).

A proximidade das fezes implicou em redução de 7,69\% na taxa de aparecimento foliar nos perfilhos de capimbraquiária (Tabela 2), o que pode ser explicado pelo maior alongamento do colmo observado nos perfilhos localizados próximos das fezes. Em verdade, o maior tamanho do pseudocolmo influencia negativamente a taxa de aparecimento foliar (Skiner \& Nelson, 1995), pois o colmo mais desenvolvido proporciona maior período de alongamento para as folhas. Esse argumento encontra respaldo no trabalho de Braz et al. (2009), que verificaram que a taxa de aparecimento foliar da $B$. decumbens cv. Basilisk diminuiu de 0,124 para 0,109 folha/perfilho.dia, quando altura das plantas passou de 10 para $40 \mathrm{~cm}$.

Coerentemente, o filocrono, que é o período entre o aparecimento de duas folhas sucessivas no perfilho, foi maior nos perfilhos localizados próximos das fezes (8,5 dias) em relação aos localizados distantes (7,7 dias). Esse maior filocrono permite inferir que estes perfilhos próximos das

Tabela 2 - Características morfogênicas do capim-braquiária sob lotação contínua em perfilhos de capim-braquiária próximos e distantes

\begin{tabular}{lccc}
\hline Variável & \multicolumn{2}{c}{ Localização das fezes } & Significância \\
\cline { 2 - 3 } & Próximas & Distantes & \\
\hline Taxa de alongamento de colmo (cm/perfilho.dia) & 0,27 & 0,15 & 0,0238 \\
Taxa de alongamento foliar (cm/perfilho.dia) & 1,72 & 1,40 & 0,0273 \\
Taxa de aparecimento foliar (folha/perfilho.dia) & 0,12 & 0,13 & 0,0932 \\
Filocrono (dia/folha) & 8,5 & 7,7 & 0,0981 \\
Taxa de senescência foliar (cm/perfilho.dia) & 0,50 & 0,28 & 0,1285 \\
Duração de vida da folha (dia) & 39,6 & 36,4 & 0,2248 \\
Taxa de acúmulo de folha (cm/perfilho.dia) & 1,21 & 1,12 & 0,1973 \\
\hline
\end{tabular}


fezes levarão mais tempo para atingir o número máximo de folhas e, portanto, para iniciar o processo de senescência foliar. Todavia, não houve efeito da proximidade das fezes sobre a taxa de senescência foliar, que apresentou valor médio de 0,39 $\mathrm{cm} /$ perfilho.dia. Esse resultado pode ser justificado pelo alto coeficiente de variação observado para esta variável (27,18\%), em decorrência da instabilidade inerente ao processo de senescência foliar. De fato, esperava-se maior senescência foliar nos perfilhos próximos das fezes, uma vez que as condições mais favoráveis ao crescimento poderiam antecipar a senescência das folhas (Nascimento Júnior \& Adese, 2004). Adicionalmente, a senescência, em geral, está associada ao alongamento do colmo sob condição de sombreamento, que provavelmente ocorreu mais intensamente na área do pasto próxima das fezes.

Não foi observado efeito da proximidade das fezes sobre a duração de vida das folhas, que apresentou valor médio de 38 dias (Tabela 2). Em estudo com a B. decumbens cv. Basilisk sob lotação contínua com bovinos, Braz et al. (2009) também não notaram efeito da altura da planta forrageira sobre essa variável, que apresentou valor médio de 38 dias.

Da mesma forma, não se constatou diferença entre a taxa de acúmulo de folhas dos perfilhos próximos e distantes das fezes, cujo valor médio foi de 1,17 cm/perfilho.dia (Tabela 2). Essa ausência de efeito no acúmulo de folhas pode estar relacionada à taxa de senescência foliar, que também não foi afetada pela proximidade das fezes. Houve influência da localização das fezes sobre o comprimento final da lâmina foliar, número de folhas com desfolhação, número de folhas mortas, número total de folha e comprimento do pseudocolmo $(\mathrm{P}<0,10)$. Todavia, o número de folhas vivas foi indiferente aos tratamentos $(\mathrm{P}>0,10)$ (Tabela 3).

Os perfilhos distantes das fezes possuíram lâminas foliares com 8,8 cm, em média. Já o comprimento final da lâmina foliar foi 25\% maior nos perfilhos localizados próximos das fezes $(11,0 \mathrm{~cm})$, o que pode ser efeito da maior disponibilidade de nutrientes no solo próximo das fezes, favorecendo assim o desenvolvimento das lâminas foliares. Nesse sentido, Fagundes et al. (2006) também constataram que o comprimento final da lâmina foliar da B. decumbens, manejada em lotação contínua, aumentou com o incremento das doses de nitrogênio.

Além disso, o maior comprimento final da lâmina foliar nos perfilhos próximos das fezes pode ser explicado pelo maior comprimento do pseudocolmo desses perfilhos (Tabela 3), uma vez que colmos maiores reduzem a taxa de aparecimento de folhas, permitindo que as lâminas foliares permaneçam por mais tempo em alongamento. De fato, o tempo entre a iniciação do primórdio foliar no meristema apical e o aparecimento subsequente da folha acima do colmo representa um período de crescimento que pode ser influenciado tanto pela taxa de alongamento da folha quanto pelo comprimento do pseudocolmo (Skinner \& Nelson, 1995).

O número de folha com desfolhação foi menor nas áreas do pasto próximas das fezes, onde se observou valor de 1,3 folhas. Já nos perfilhos distantes esse valor foi, em média, de 3,6 folhas pastejadas. Isso indica que perfilhos localizados próximos das fezes foram visitados e desfolhados pelos bovinos de forma menos frequente quando comparados aos perfilhos distantes das fezes. Nesse contexto, Willians \& Haynes (1995) relataram que a área do pasto rejeitada pelos animais pode ser 5 a 12 vezes maior do que a área do pasto com fezes, e o período dessa rejeição pode ser de 40 dias a 18 meses, de acordo com as condições edafoclimáticas.

Essa rejeição da forrageira em áreas do pasto próximas às fezes também pode ter contribuído para a maior taxa de crescimento do capim-braquiária, o que explicaria, em parte, as maiores taxas de alongamento foliar e de colmo, bem como as menores taxas de aparecimento foliar nos perfilhos localizados próximos das fezes (Tabela 2).

O número de folha morta também foi maior nos perfilhos próximos das fezes do que nos distantes (Tabela 3), indicando que a frequência e a intensidade com que os primeiros foram pastejados pelos bovinos foram menores, o que poderia ter implicado em maior perda de forragem por senescência. Esse indício é coerente, porque plantas de B. decumbens mais altas $(40 \mathrm{~cm})$, comuns em locais do pasto com menor frequência ou intensidade de desfolhação, possuem maior senescência foliar em comparação a plantas mais baixas (10 cm) (Braz et al., 2009). O maior número de folhas mortas nos perfilhos próximos das fezes também

Tabela 3 - Características estruturais de perfilhos de capim-braquiária sob lotação contínua em áreas próximas e distantes de fezes bovinas

\begin{tabular}{lccc}
\hline Variável & \multicolumn{2}{c}{ Localização das fezes } & Significância \\
\cline { 2 - 3 } & Próximas & Distantes & \\
\hline Comprimento final da lâmina foliar (cm) & 11,0 & 8,8 & 0,0005 \\
Número de folhas com desfolhação (folha) & 1,3 & 3,6 & 0,0177 \\
Número de folhas mortas (folha) & 2,8 & 1,9 & 0,0479 \\
Número total de folhas (folha) & 7,4 & 6,6 & 0,0521 \\
Comprimento do pseudocolmo (cm) & 14,7 & 8,5 & 0,0427 \\
Número de folhas vivas (folha) & 4,69 & 4,74 & 0,1612 \\
\hline
\end{tabular}


poderia ser reflexo da maior disponibilidade de nutrientes nessa região do pasto, que aumenta o desenvolvimento da forrageira.

Por outro lado, não foi observado efeito da proximidade das fezes no número de folhas vivas, que apresentou valor médio de 4,7 folhas/perfilho (Tabela 3). O valor dessa variável é relativamente estável na ausência de deficiências hídricas ou nutricionais e em condições de manejo (Nabinger \& Pontes, 2001). Portanto, as condições experimentais neste estudo não foram suficientes para promover mudanças no número de folhas vivas do capimbraquiária. Esse resultado corrobora aquele obtido por Fagundes et al. (2006), que também não observaram efeito de doses de nitrogênio sobre o número de folhas vivas da B. decumbens manejada sob lotação contínua, que apresentou valor médio de 5,1 folhas/perfilho.

Já o número total de folha por perfilho foi $12,12 \%$ maior quando próximos das fezes (Tabela 3), provavelmente em decorrência do maior número de folhas mortas nesses perfilhos. De acordo com Garcez Neto et al. (2002), o número total de folhas expressa o potencial máximo de assimilação de carbono, o que permite inferir que os perfilhos próximos das fezes tiveram maior capacidade de acumular folhas, possivelmente, em razão da maior disponibilidade de nutrientes nesse local do solo. Em verdade, o número total de folha por perfilho da B. decumbens é maior em plantas adubadas com nitrogênio, em comparação àquelas não adubadas (Silva et al., 2009).

O comprimento do pseudocolmo nos perfilhos próximos das fezes foi 72,94\% maior que o dos distantes (Tabela 3), o que pode ser explicado por dois fatores já mencionados para outras variáveis, quais sejam, maior disponibilidade de nutrientes no solo próximo às fezes, o que proporcionou condições favoráveis ao crescimento dos perfilhos; e a ocorrência de rejeição da forrageira nas áreas adjacentes às fezes. O maior comprimento de pseudocolmos também pode ser resultante da maior taxa de alongamento de colmos observada nestes perfilhos (Tabela 2).

Além das características morfogênicas e estruturais de perfilhos individuais, a quantificação da densidade populacional das distintas categorias de perfilhos também é importante para caracterizar as áreas do pasto de acordo com a localização das fezes. Nesse sentido, o número de perfilhos vegetativos foi menor ( 1.552 perfilhos $/ \mathrm{m}^{2}$ ) na área próxima que na distante $\left(1.760\right.$ perfilhos $\left./ \mathrm{m}^{2}\right)$ das fezes (Tabela 4). O maior crescimento da forrageira, proporcionado pela deposição de nutrientes oriundos das fezes e também a rejeição do pasto pelo animal, resultaram em pastos mais altos próximos às placas de fezes. Com isso, houve sombreamento de perfilhos vegetativos mais novos e de menor tamanho, que podem ter morrido. Silva et al. (2008) também constatou menor número de perfilho vegetativo (1.404 perfilho $/ \mathrm{m}^{2}$ ) em plantas de B. decumbens mais altas $(40 \mathrm{~cm})$, característica comum das plantas nos locais próximos das fezes.

Contrariamente ao número de perfilho vegetativo, a densidade populacional de perfilho reprodutivo foi superior na área próxima (162 perfilhos $/ \mathrm{m}^{2}$ ) que naquela distante (60 perfilhos $/ \mathrm{m}^{2}$ ) das fezes (Tabela 4). Nesta última, possivelmente, o pastejo ocorreu de forma mais frequente, haja vista que não houve a rejeição da forragem próxima das fezes. Com o pastejo, houve a eliminação do meristema apical daqueles perfilhos que iniciaram a fase reprodutiva, diminuindo a ocorrência de perfilhos reprodutivos nessas áreas. Já nos locais próximos das fezes a rejeição do pasto pelo animal possibilitou o desenvolvimento dos perfilhos vegetativos em reprodutivos, de acordo com o ciclo fenológico da gramínea. Maior número de perfilho reprodutivo de B. decumbens também foi observado por Silva et al. (2008) em locais do mesmo pasto com plantas mais altas, situação comum aos locais do pasto próximos das fezes de bovinos.

A área distante das fezes apresentou maior número de perfilho morto (Tabela 4). Esse resultado pode ter sido ocasionado pela maior frequência de pastejo nessas áreas, causando maior distúrbio nas plantas e, por conseguinte, resultando em maior mortalidade de perfilhos. Era esperado maior número de perfilhos mortos em áreas adjacentes às fezes devido ao maior sombreamento dos perfilhos menores, mas essa hipótese não foi confirmada. Possivelmente, o microclima diferenciado formado com a deposição das fezes proporcionou condições favoráveis à maior sobrevivência

Tabela 4 - Densidades populacionais de perfilhos do capim-braquiária sob lotação contínua em áreas próximas e distantes das fezes

\begin{tabular}{lccc}
\hline Perfilhos $/ \mathrm{m}^{2}$ & \multicolumn{2}{c}{ Localização das fezes } & Significância \\
\cline { 2 - 4 } & Próximas & Distantes & \\
\hline Vegetativos & 1552 & 1760 & 0,0233 \\
Reprodutivos & 162 & 60 & 0,0484 \\
Mortos & 453 & 606 & 0,0315 \\
Totais & 2167 & 2427 & 0,0177 \\
Vivos & 1714 & 1820 & 0,2796 \\
\hline
\end{tabular}


dos perfilhos, o que fez com que o maior sombreamento nos locais próximos das fezes, promovido pelos perfilhos maiores, não fosse suficiente para provocar mortalidade dos perfilhos menores.

Com relação ao número de perfilhos vivos, não se constatou diferença entre os tratamentos (Tabela 4). Os perfilhos vivos são constituídos de perfilhos vegetativos e reprodutivos, que apresentaram padrão de resposta antagônico. Com isso, houve compensação entre densidades populacionais de perfilhos vegetativos e reprodutivos, tornando semelhante o número de perfilhos vivos. Por outro lado, as áreas distantes das fezes possuíram maior número total de perfilho (Tabela 4) porque continham mais perfilhos vegetativos e mortos, em comparação às áreas próximas das fezes.

A consideração conjunta dos dados de morfogênese e de densidade populacional de perfilhos permitiu mensurar as taxas de acúmulo de forragem, expressas em $\mathrm{kg} / \mathrm{ha}$.dia de MS, nas áreas distintas dentro de cada piquete de capim-braquiária (Tabela 5). As taxas de alongamento de colmo e de folha foram maiores na área próxima das fezes, quando comparada à área distante. Esses resultados podem ser atribuídos à maior disponibilização de nutrientes no solo oriundos das placas de fezes. Possivelmente, esses nutrientes foram absorvidos pelo sistema radicular do capim-braquiária, o que resultou em maior alongamento do colmo e das folhas nos perfilhos. De fato, em condições de maior disponibilidade de nutrientes, como o nitrogênio, o acúmulo de forragem em pasto de $B$. decumbens é maior (Moreira et al., 2009).
Como consequência das maiores produções de colmo e folha, também foi constatado maior taxa de crescimento total (folha mais colmo) do capim-braquiária nas áreas do pasto próximas das fezes (Tabela 5). Isso corrobora os dados obtidos por Braz et al. (2002), que estudaram a disponibilização dos nutrientes das fezes de bovinos em pasto de $B$. decumbens e constataram que as placas de fezes influenciaram a produção de matéria seca de forragem em um raio de até $25 \mathrm{~cm}$ das placas de fezes.

Não foi verificado efeito da placa de fezes sobre a taxa de senescência foliar (TSeF) do capim-braquiária (Tabela 5). A ausência de efeito significativo provavelmente está relacionada ao alto coeficiente de variação dessa variável resposta. De fato, era esperado maior senescência foliar próximo às placas de fezes devido à maior taxa de crescimento da forrageira. De acordo com Nascimento Júnior \& Adese (2004), frequentemente, o que se observa é o aumento nas taxas de senescência foliar sob condições de alta disponibilidade de nutrientes, como o nitrogênio.

A taxa de acúmulo de folhas também não diferiu entre as áreas próximas e distantes das fezes (Tabela 5). Isso ocorreu porque a maior taxa de alongamento foliar foi compensada pela maior taxa de senescência na área próxima das fezes. O contrário ocorreu na região distante das fezes. Por outro lado, a taxa de acúmulo de forragem, que é a diferença entre a taxa de crescimento total e a taxa de sencescência foliar, foi 29,05\% superior na área do pasto próxima das fezes (Tabela 5), o que é justificado, principalmente, pela maior taxa de crescimento total observada próxima das fezes.

Tabela 5 - Taxas de produção de tecidos do capim-braquiária em áreas próximas e distantes das fezes de bovinos

\begin{tabular}{lccc}
\hline Variável & \multicolumn{2}{c}{ Localização das fezes } & \multirow{2}{*}{ Significância } \\
\cline { 2 - 3 } & Próximas & Distantes & \\
\hline Taxa de alongamento de colmo (kg/ha.dia de MS) & 57,84 & 0,03433 \\
Taxa de alongamento foliar (kg/ha.dia de MS) & 109,81 & 32,66 & 12,97 \\
Taxa de senescência foliar (kg/ha.dia de MS) & 32,08 & 91,82 & 0,06886 \\
Taxa de acúmulo de folha (kg/ha.dia de MS) & 77,73 & 79,43 & 0,16519 \\
Taxa de crescimento total (colmo + folha) (kg/ha.dia de MS) & 167,65 & 12,39 & 0,2321 \\
Taxa de acúmulo de forragem (kg/ha.dia de MS) & 135,57 & 105,05 & 0,02888 \\
\hline
\end{tabular}

\section{Conclusões}

A deposição de fezes bovinas modifica as características morfogênicas e estruturais de B. decumbens. O fluxo de tecidos do capim-braquiária nas proximidades das fezes é mais intenso. Perfilhos sob pastejo e em locais próximos de fezes de bovinos possuem lâminas foliares e colmos mais compridos, maior número de folhas senescentes e totais, além de menor número de folhas pastejadas. O número de perfilhos reprodutivos é menor, enquanto o de perfilhos vegetativos, mortos e totais de B. decumbens, sob pastejo e em lotação contínua, é maior nas áreas distantes das fezes. O acúmulo de forragem da $B$. decumbens é maior nas áreas próximas às fezes de bovinos distribuídas naturalmente na pastagem. 


\section{Referências}

BRAZ, S.P.; NASCIMENTO JÚNIOR, D.; CANTARUTTI, R.B. et al. Aspectos quantitativos do processo de reciclagem de nutrientes pelas fezes de bovinos sob pastejo em pastagem de Brachiaria decumbens na Zona da Mata de Minas Gerais. Revista Brasileira de Zootecnia, v.31, n.2, p.858-865, 2002 (supl.).

BRAZ, T.S.G.; SANTOS, M.E.R.; FONSECA, D.M. et al. Características morfogênicas do capim-braquiária com variação de alturas no mesmo pasto. In: CONGRESSO DE FORRAGICULTURA E PASTAGENS, 3., 2009, Lavras. Anais... Lavras: Universidade Federal de Lavras, 2008. (CD-ROM).

CHAPMAN, D.F.; LEMAIRE, G. Morphogenic and structural determinants of plant regrowth after defoliation. INTERNATIONAL GRASSLAND CONGRESS, 17., 1993, Palmestron North. Proceedings... Palmestron North: Massey University, 1993. p.93-104.

CHAPMAN, D.F.; LEMAIRE, G. Morfhogenetic and structural determinants of plant regrowth after defoliation. In: BACKER, M.J. (Ed.) Grasslands for our world. Wellington: SIR Oublishing, 1993. p.55-56.

CARVALHO, P.C.F.; RIBEIRO FILHO, H.M.N.; POLI, C.H.E.C. et al. Importância da estrutura da pastagem na ingestão e seleção de dietas pelo animal em pastejo. In: REUNIÃO ANUAL DA SOCIEDADE BRASILEIRA DE ZOOTECNIA, 38., 2001, Piracicaba. Anais... Piracicaba: ESALQ, 2001. p.883-871.

EMPRESA BRASILEIRA DE PESQUISA E AGROPECUÁRIA EMBRAPA. Sistema brasileiro de classificação dos solos. Brasília: Embrapa-SPI; Rio de Janeiro: Embrapa-CNPS, 1999. 412p.

FAGUNDES, J.A.; FONSECA, D.M.; MISTURA, C. et al. Características morfogênicas e estruturais do capim-braquiária em pastagem adubada com nitrogênio avaliadas nas quatro estações do ano. Revista Brasileira de Zootecnia. v.35, n.1, p.21-29, 2006.

GARCEZ NETO, A.F.; NASCIMENTO JÚNIOR, D.; REGAZZI, A.J. et al. Respostas morfogênicas e estruturais de Panicum maximum cv. Mombaça sob diferentes níveis de adubação nitrogenada e alturas de corte. Revista Brasileira de Zootecnia, v.31, n.5, p.1890-1900, 2002.

GOMIDE, J.A.; CÂNDIDO, M.J.D.; ALEXANDRINO, E. As interfaces solo, planta e animal da exploração da pastagem. In:
FORRAGICULTURA E PASTAGENS: TEMAS EM EVIDÊNCIA - SUSTENTABILIDADE, 4., 2003, Lavras. Anais... Lavras: Editora UFLA, 2003. p.75-116.

GOMIDE, C.A.M.; GOMIDE, J.A. Morfogênese de cultivares de Panicum maximum Jacq. Revista Brasileira de Zootecnia, v.29, n.2, p.341-348, 2000.

LEMAIRE, G.; CHAPMAN, D. Tissue flows in grazed plant communities. In: HODGSON, J.; ILliUS, A.W. (Eds.) The ecology and management of grazing systems. Guildfor: Cab International. 1996. p.3-36.

MOOT, G.O.; POPENOE, H.L. Grasslands. In: ALVIN, P.T.; KOSLOWSK, T.T. (Eds.) Ecophysiology of tropical crops. New York: Academic Press, 1977. p.157-186.

MOREIRA, L.M.; MARTUSCELLO, J.A.; FONSECA, D.M. et al. Perfilhamento, acúmulo de forragem e composição bromatológica do capim-braquiária adubado com nitrogênio. Revista Brasileira de Zootecnia, v.38, n.9, p.1675-1684, 2009.

NABINGER, C.; PONTES, L.S. Morfogênese de plantas forrageiras e estrutura do pasto. In: REUNIÃO ANUAL DA SOCIEDADE BRASILEIRA DE ZOOTECNIA, 38., 2001, Piracicaba. Anais... Piracicaba: Sociedade Brasileira de Zootecnia, 2001. p.755-771.

NASCIMENTO JÚNIOR, D.; ADESE, B. Acúmulo de biomassa na pastagem. In: SIMPÓSIO SOBRE MANEJO ESTRATÉGICO DA PAStagem, 2., 2004, Viçosa, MG. Anais... Viçosa, MG: UFV, 2004. p.289-330.

SILVA, C.C.F.; BONOMO, P.; PIRES, A.J.V. et al. Características morfogênicas e estruturais de duas espécies de braquiária adubadas com diferentes doses de nitrogênio. Revista Brasileira de Zootecnia, v.38, n.4, p.657-661, 2009.

SILVA, G.P.; SANTOS, M.E.R.; FONSECA, D.M. et al. Densidade populacional de perfilhos em áreas do pasto de capim-braquiária com alturas variáveis. In: CONGRESSO NORDESTINO DE PRODUÇÃO ANIMAL, 5., 2008, Aracaju. Anais... Aracaju: Sociedade Nordestina de Produção Animal, 2008. (CD-ROM)

SKINNER, R.H.; NELSON, C.J. Elongation of the grass leaf and its relationship phillochron. Crop Science, v.35, n.1, p.4-10, 1995.

WILLIANS, P.H.; HAYNES, R.J. Effect of sheep, deer and cattle dung on herbage production and soil nutrient content. Grass and Forage Science, v.50, p.263-271, 1995.

UNIVERSIDADE FEDERAL DE VIÇOSA - UFV. SAEG - Sistema de análises estatísticas e genéticas. Versão 8.1. Viçosa, MG: 2003. (Apostila). 